\title{
Dependence of vacuole disruption and independence of potassium ion efflux in fungicidal activity induced by combination of amphotericin B and allicin against Saccharomyces cerevisiae
}

\begin{abstract}
Akira Ogita $^{1,2}$, Masahiro Yutani ${ }^{1}$, Ken-ichi Fujita ${ }^{1}$ and Toshio Tanaka ${ }^{1}$
Allicin selectively enhances the fungicidal activity of amphotericin B (AmB). It also accelerates AmB-induced vacuole disruption but does not affect AmB-induced potassium ion efflux in Saccharomyces cerevisiae and Candida albicans. The fungicidal activity of AmB alone or combined with allicin was further evaluated based on the relationship among cell viability, vacuole disruption and potassium ion efflux in $S$. cerevisiae. Lethality and vacuole disruption caused by AmB alone were completely restricted when $\mathrm{K}^{+}$and $\mathrm{Mg}^{2+}$ were added to the growth medium. On the other hand, in identical conditions, the combination of AmB and allicin induced both lethality and vacuole disruption. S. cerevisiae $\Delta$ erg 6 cells, which lack ergosterol in plasma membrane, were mostly resistant to $\mathrm{AmB}$ as well as the combination of AmB and allicin against both lethality and vacuole disruption. The incorporation of AmB into the cytoplasm of $\Delta$ erg 6 cells was significantly reduced in comparison with that in parent cells, regardless of the presence of allicin. Our results suggest that the fungicidal activity of AmB combined with allicin is involved in vacuole disruption but not in potassium ion efflux, and that the expression of allicin-mediated activity of AmB requires the presence of ergosterol in the plasma membrane.
\end{abstract}

The Journal of Antibiotics (2010) 63, 689-692; doi:10.1038/ja.2010.115; published online 13 October 2010

Keywords: amphotericin B; ergosterol; Saccharomyces cerevisiae; vacuole

\section{INTRODUCTION}

Amphotericin B (AmB), a typical polyene macrolide antifungal antibiotic, is widely used for the treatment of many systemic mycoses. Its mechanism of action is generally accepted as follows. AmB binds to ergosterol in fungal plasma membranes, alters the permeability of plasma membrane (for example, by forming pores that leak potassium ions, resulting in loss of intracellular $\mathrm{K}^{+}$) and then causes the death of fungal cells. ${ }^{1,2}$ Supply of $\mathrm{K}^{+}$and $\mathrm{Mg}^{2+}$ from the external environment protects the AmB-treated cells from death, ${ }^{3}$ indicating the direct involvement of intracellular $\mathrm{K}^{+}$in cell viability. On the other hand, AmB-induced loss of intracellular $\mathrm{K}^{+}$results in various secondary effects, including ATP depletion and subsequent inhibition of protein synthesis. Therefore, loss of intracellular $\mathrm{K}^{+}$might accelerate cell death. ${ }^{4}$ In addition, AmB induced oxidative stress accompanying cell death in the pathogenic fungus Candida albicans. ${ }^{5}$ Moreover, AmB was able to permeate through the plasma membrane and then to invade the fungal cytoplasm. Cytoplasmic AmB might fragment the vacuole membrane, thereby disrupting vacuoles. ${ }^{6}$ Thus, the exact fungicidal mechanism of $\mathrm{AmB}$ has not yet been fully understood; therefore AmB-induced lethality cannot be simply explained only by the disturbance in biophysical functions in the plasma membrane. ${ }^{7,8}$

Allicin, an allyl-sulfur compound from garlic, exerts various biological effects such as antimicrobial and anticancer activities. ${ }^{9,10}$ We have recently reported that allicin selectively enhances the fungicidal activity of AmB. In addition, allicin accelerated AmB-induced vacuole disruption but did not affect AmB-induced leakage of intracellular $\mathrm{K}^{+}$in Saccharomyces cerevisiae and C. albicans. ${ }^{6,11}$ Allicin alone did not induce the loss of intracellular $\mathrm{K}^{+}$nor the disruption of vacuole membrane. ${ }^{6,11}$ Furthermore, we found that allicin enhanced AmBinduced vacuole disruption by inhibiting ergosterol trafficking from the plasma membrane to the vacuole membrane. ${ }^{12}$ The constant ergosterol transport to the vacuole membrane may protect yeast cells from AmB-induced vacuole disruption. ${ }^{12}$ The vacuole-targeting fungicidal activity, which depends on the structure of the macrocyclic ring, might elucidate at least in part the primary mechanism of the lethal action of AmB. ${ }^{13}$ However, the transport mechanism

${ }^{1}$ Department of Biology and Geosciences, Graduate School of Science, Osaka City University, Osaka, Japan and ${ }^{2}$ Research Center for Urban Health and Sports, Osaka City University, Osaka, Japan

Correspondence: Dr K Fujita or Dr T Tanaka, Department of Biology and Geosciences, Graduate School of Science, Osaka City University, 3-3-138 Sugimoto, Sumiyoshi-ku, Osaka 558-8585, Japan.

E-mail: kfujita@sci.osaka-cu.ac.jp or tanakato@sci.osaka-cu.ac.jp

Received 13 April 2010; revised 21 September 2010; accepted 23 September 2010; published online 13 October 2010 
of $\mathrm{AmB}$ into the cytoplasm is unclear, as well as the relationship between vacuole disruption and $\mathrm{AmB}$-induced alteration of membrane permeability. In this study, we examined the relationship among cell viability, vacuole disruption and potassium ion efflux in cells treated with $\mathrm{AmB}$ in the presence or absence of allicin. Moreover, we discuss the significance of ergosterol content in plasma membrane on the vacuole-targeting activity of AmB to clarify the primary mechanism underlying AmB lethality.

\section{MATERIALS AND METHODS}

\section{Measurement of yeast cell viability}

S. cerevisiae W303-1A wild-type strain (provided by Dr T Nakamura, Osaka City University, Japan) and its ERG6 gene deletion mutants (National BioResource Project, Japan) were used in the following experiments to examine the effects of AmB and allicin on the properties of cells, including viability. Cells were grown overnight in YPD medium containing $1 \%$ yeast extract (Difco Laboratories, Detroit, MI, USA), 2\% Bacto-peptone (Difco Laboratories) and $2 \%$ glucose at $30^{\circ} \mathrm{C}$ with vigorous shaking. After washing with distilled water, the cells were immediately diluted with distilled water to a density of $1 \times 10^{6}$ cells per $\mathrm{ml}$. The cells were then incubated in the presence or absence of each compound with vigorous shaking at $30^{\circ} \mathrm{C}$. Viable cell count was determined by counting the number of colony-forming units after $48 \mathrm{~h}$ of incubation at $30^{\circ} \mathrm{C}$ in YPD medium containing $1.8 \%(\mathrm{w} / \mathrm{v})$ agar.

\section{Leakage of potassium ions}

Cells were harvested by centrifugation, washed with $50 \mathrm{~mm}$ Tris- $\mathrm{HCl}$ buffer $(\mathrm{pH}$ 7.4), and suspended in the same buffer to obtain a density of $1 \times 10^{8}$ cells per $\mathrm{ml}$. The cell suspensions were then shaken with $5 \mu \mathrm{M} \mathrm{AmB}$ in the presence or absence of $120 \mu \mathrm{M}$ allicin at $30^{\circ} \mathrm{C}$ for $60 \mathrm{~min}$. The supernatants obtained after cell removal by centrifugation were assayed for $\mathrm{K}^{+}$content using a $\mathrm{K}^{+}$assay kit (HACH, Floriffoux, Belgium) based on the tetraphenylborate method. ${ }^{14}$

\section{Vacuole staining}

Vacuoles were visualized by staining with the fluorescent probe FM4-64 as follows. ${ }^{15}$ Cells from the overnight culture in YPD medium were suspended in a freshly prepared medium to obtain a density of $1 \times 10^{7}$ cells per ml. After incubation with $5 \mu \mathrm{M}$ FM4- 64 at $30^{\circ} \mathrm{C}$ for $30 \mathrm{~min}$, the cells were collected by centrifugation, washed twice and then suspended in distilled water at a final density of $1 \times 10^{7}$ cells per $\mathrm{ml}$. The cells were incubated in the absence or presence of each compound with vigorous shaking at $30^{\circ} \mathrm{C}$ for $60 \mathrm{~min}$, and then observed under a phase-contrast microscope and a fluorescence microscope with excitation at $520-550 \mathrm{~nm}$ and emission at $580 \mathrm{~nm}$.

\section{Measurement of AmB content by HPLC}

Cells from the overnight culture in YPD medium were collected by centrifugation, washed twice with phosphate-buffered saline (PBS) and then suspended in PBS to obtain a final density of $1 \times 10^{8}$ cells per ml. The cell suspension was incubated with $20 \mu \mathrm{M} \mathrm{AmB}$ in the absence or presence of $120 \mu \mathrm{M}$ allicin at $30^{\circ} \mathrm{C}$ for $60 \mathrm{~min}$. The supernatant obtained after the removal of cells by centrifugation was used as the supernatant fraction. The cell pellets were washed twice with PBS and then suspended in PBS at a density of $1 \times 10^{8}$ cells per ml. After the addition of yeast lytic enzyme at a final concentration of $6 \mathrm{mg} \mathrm{ml}^{-1}$ and $0.5 \%$ 2-mercaptoethanol, the cells were incubated with gentle agitation at $30^{\circ} \mathrm{C}$ for $60 \mathrm{~min}$ or longer to ensure complete cell lysis. The supernatant obtained after centrifugation $(5000 \mathrm{~g})$ of the cell lysate at $4{ }^{\circ} \mathrm{C}$ for $10 \mathrm{~min}$ was used as the cytoplasmic fraction. The pellets were washed twice with PBS. The final precipitate obtained was decomposed by repeated vortexing with a mixture of water/methanol/chloroform (30:20:50, $/ / \mathrm{v})$ at room temperature. The upper water-soluble layer was used as the plasma membrane fraction including phospholipids. $^{6}$

The fractions obtained above were assayed for AmB content using HPLC with a reverse-phase column $\left(4.6 \times 250 \mathrm{~mm}\right.$, COSMOSIL $5 \mathrm{C}_{18}$-MS-II, Nacalai Tesque, Kyoto, Japan). The chromatographic solvents were eluted at room temperature with a mobile phase consisting of a mixture of $0.1 \mathrm{M}$ sodium acetate $(\mathrm{pH} 4.0) /$ acetonitrile $(60: 40, \mathrm{v} / \mathrm{v})$ at a flow rate of $1.0 \mathrm{ml} \mathrm{min}^{-1}$. $\mathrm{AmB}$ was detected at $405 \mathrm{~nm} .{ }^{16}$

\section{Chemicals}

AmB was purchased from Sigma Aldrich (St Louis, MO, USA). Allicin was obtained from LKT Laboratories (St Paul, MN, USA). Yeast lytic enzyme and FM4-64 were from ICN Biomedicals (Aurora, OH, USA) and Molecular Probes (Eugene, OR, USA), respectively. The other chemicals used were of analytical reagent grade and purity.

\section{RESULTS AND DISCUSSION}

\section{Fungicidal activity of $\mathrm{AmB}$ and allicin}

The addition of $\mathrm{K}^{+}$into the medium preserves intracellular $\mathrm{K}^{+}$content in AmB-treated cells of $S$. cerevisiae, ${ }^{3}$ whereas the addition of $\mathrm{Mg}^{2+}$ maintains membrane integrity and cell metabolism. ${ }^{17,18}$ Therefore, coaddition of both $\mathrm{K}^{+}$and $\mathrm{Mg}^{2+}$ markedly restricts both the growthinhibitory and lethal effects of AmB. ${ }^{3}$ On the other hand, $\Delta$ erg6 cells cannot convert zymosterol to fecosterol in the ergosterol biosynthetic pathway, leading to a reduction of ergosterol content in the plasma membrane and thereby increasing the resistance to polyene antibiotics such as AmB. ${ }^{19}$ We first examined whether allicin could enhance the

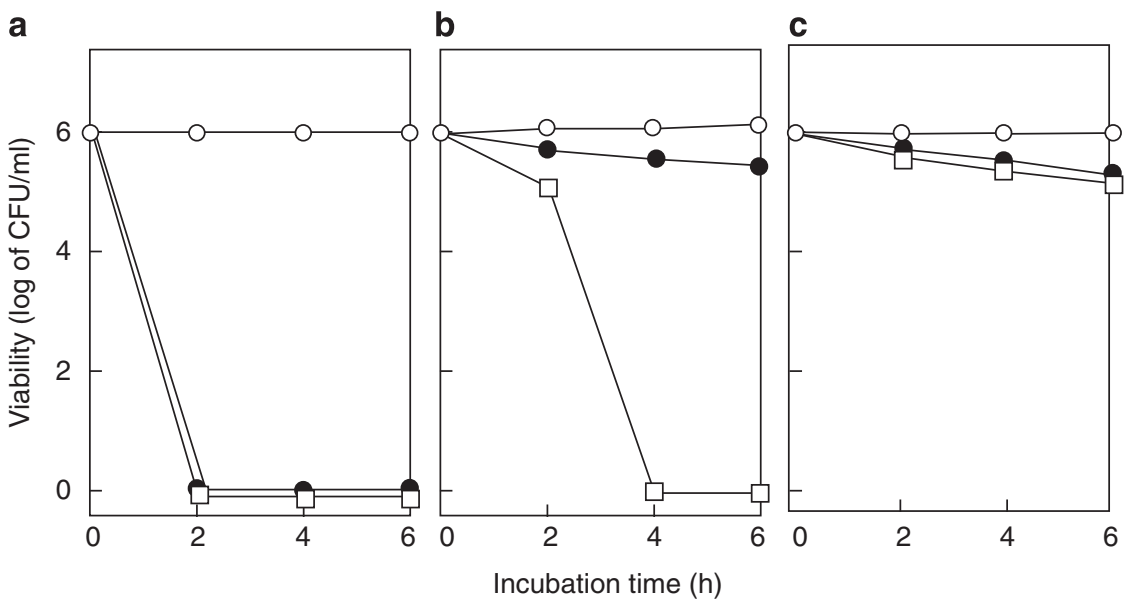

Figure 1 Fungicidal activity of amphotericin B (AmB) in the absence or presence of allicin against parent (a, b) and $\Delta$ erg6 (c) cells of $S$. cerevisiae. Cells $\left(1 \times 10^{6}\right.$ cells per $\left.\mathrm{ml}\right)$ were incubated with none $(\bigcirc), 5 \mu \mathrm{m} \mathrm{AmB}(0)$ and a combination of $5 \mu \mathrm{m} A \mathrm{mB}$ and $120 \mu \mathrm{m}$ allicin $(\square)$ in distilled water, in the absence $(\mathbf{a}, \mathbf{c})$ or presence (b) of $85 \mathrm{~mm} \mathrm{KCl}$ and $45 \mathrm{~mm} \mathrm{MgCl}_{2}$ at $30{ }^{\circ} \mathrm{C}$. 
fungicidal activity of $\mathrm{AmB}$ in the presence or absence of $\mathrm{K}^{+}$and $\mathrm{Mg}^{2+}$ against parent and $\Delta$ erg6 strains of $S$. cerevisiae W303-1A. Five micromolars of $\mathrm{AmB}$, as well as the combination of $5 \mu \mathrm{M} \mathrm{AmB}$ and $120 \mu \mathrm{M}$ allicin, showed fungicidal activity against the parent cells in the absence of $\mathrm{K}^{+}$and $\mathrm{Mg}^{2+}$ (Figure 1a). The parent cells were resistant to $5 \mu \mathrm{M} A \mathrm{mB}$ in distilled water supplemented with $\mathrm{K}^{+}$and $\mathrm{Mg}^{2+}$ (Figure $1 \mathrm{~b}$ ). This supported the previous report ${ }^{17}$ that the addition of both $\mathrm{K}^{+}$and $\mathrm{Mg}^{2+}$ could decrease the lethal effect of AmB. In contrast, the combination of $5 \mu \mathrm{M} \mathrm{AmB}$ and $120 \mu \mathrm{M}$ allicin showed fungicidal activity in the presence of $\mathrm{K}^{+}$and $\mathrm{Mg}^{2+}$ (Figure 1b). Namely, AmB expressed fungicidal activity in combination with allicin even when the intracellular concentration of $\mathrm{K}^{+}$was maintained at normal levels in $\mathrm{K}^{+}$-enriched medium. On the other hand, $\Delta$ erg6 cells were resistant to $\mathrm{AmB}$ combined with allicin in addition to $\mathrm{AmB}$ alone (Figure 1c). These results suggest that the allicin-mediated fungicidal activity of AmB probably depends on the ergosterol content in plasma membrane, as well as the case of the activity of $\mathrm{AmB}$ alone, but not on the loss of intracellular $\mathrm{K}^{+}$due to dysfunction of the plasma membrane. a

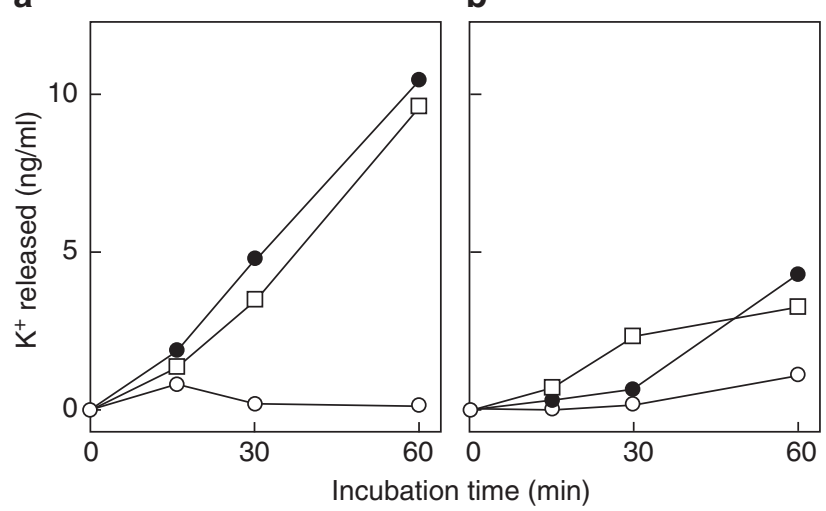

Figure 2 Promotive effects of amphotericin $B(A m B)$ and the combination of $A m B$ and allicin on leakage of $\mathrm{K}^{+}$from parent (a) or $\Delta$ erg6 (b) cells of S. cerevisiae. Cells $\left(1 \times 10^{8}\right.$ cells per $\left.\mathrm{ml}\right)$ were incubated in $50 \mathrm{~mm}$ Tris- $\mathrm{HCl}$ buffer $(\mathrm{pH}$ 7.4) containing none $(O), 5 \mu \mathrm{M} A \mathrm{mB}(\bullet)$, and a combination of $5 \mu \mathrm{m} \mathrm{AmB}$ and $120 \mu \mathrm{m}$ allicin $(\square)$ at $30^{\circ} \mathrm{C}$

\section{Potassium ion efflux induced by $\mathrm{AmB}$ and allicin}

Ion-permeability change by $\mathrm{AmB}$ in fungal cells occurs because of the pores formed by ergosterol directly bound to $\mathrm{AmB}$ in the plasma membrane. ${ }^{20}$ In $\Delta$ erg6 cells, the reduced content of ergosterol decreases the number of target molecules for AmB. ${ }^{19}$ As shown in Figure $2 \mathrm{a}$, the rate of $\mathrm{K}^{+}$release caused by $\mathrm{AmB}$ in parent cells was similar in conditions with or without allicin, indicating the ionpermeability change induced by AmB. Allicin does not seem to have a role in this $\mathrm{K}^{+}$efflux. Contrary to the results obtained with parent cells, $\Delta$ erg 6 cells did not exhibit such a damage as the ion-permeability change caused by AmB, even if allicin was added simultaneously with $\mathrm{AmB}$ (Figure 2b). The fungicidal activity of AmB combined with allicin was expressed under conditions with or without $\mathrm{K}^{+}$on parent cells (see Figure $1 \mathrm{~b}$ ). These results indicate that cell death induced by the combination of $\mathrm{AmB}$ and allicin was unrelated to the ion-permeability change caused by AmB.

\section{Enhancement effects of allicin on vacuole disruption}

We further examined whether allicin could amplify the vacuoledisruptive activity of $\mathrm{AmB}$ when the intracellular $\mathrm{K}^{+}$concentration was maintained by external addition of $\mathrm{K}^{+}$and $\mathrm{Mg}^{2+}$ in parent cells and $\Delta$ erg6 cells. In these experiments, conditions with $\mathrm{K}^{+}$and $\mathrm{Mg}^{2+}$ were applied only to parent cells because $\mathrm{K}^{+}$did not leak in $\Delta$ erg6 cells treated with $\mathrm{AmB}$ (see Figure $2 \mathrm{~b}$ ). AmB disrupted vacuoles in the absence of $\mathrm{K}^{+}$and $\mathrm{Mg}^{2+}$ (Figure 3a), and eventually caused cell death. The coexistence of $\mathrm{K}^{+}$and $\mathrm{Mg}^{2+}$ maintained the normal morphology of vacuoles in parent cells treated with $\mathrm{AmB}$ alone (Figure $3 \mathrm{~b}$ ). Cells remained viable in this treatment (see Figure 1b). These suggested that the maintenance of intracellular $\mathrm{K}^{+}$concentrations might restrict the cell death, which was induced by both the plasma membrane permeability change and the vacuole disruption caused by $\mathrm{AmB}$ alone. On the other hand, the combination of $\mathrm{AmB}$ and allicin disrupted vacuoles as well as the case of $\mathrm{AmB}$ alone in the absence of $\mathrm{K}^{+}$and $\mathrm{Mg}^{2+}$, followed by cell death, under conditions with or without $\mathrm{K}^{+}$and $\mathrm{Mg}^{2+}$ (Figures $3 \mathrm{a}$ and $\mathrm{b}$ ). These results indicated that the inhibition of ergosterol trafficking from plasma membrane to vacuoles caused by allicin was able to overcome the vacuole stabilization provided by adding $\mathrm{K}^{+}$and $\mathrm{Mg}^{2+}$. On the other hand, vacuoles of $\Delta$ erg6 cells were not disrupted by both $\mathrm{AmB}$ alone and the combination of $\mathrm{AmB}$ and allicin (Figure $3 \mathrm{c}$ ). Although lethality induced by a

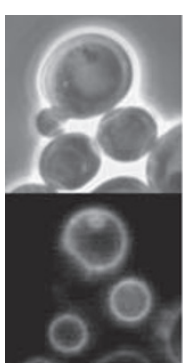

Lethal

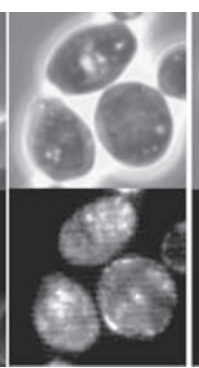

None

$\mathrm{AmB}$
Lethal

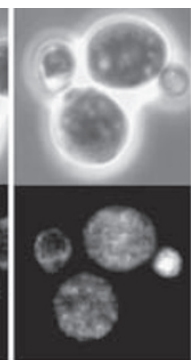

$\mathrm{AmB}$

+ Allicin b

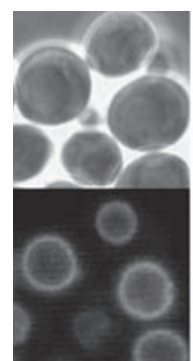

None

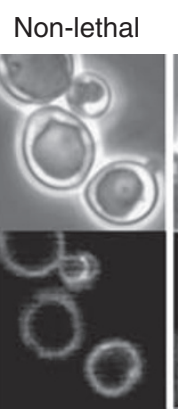

$\mathrm{AmB}$

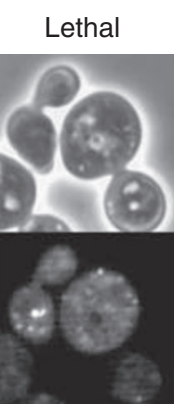

$\mathrm{AmB}$ + Allicin

D.W. $+\mathrm{K}^{+}$and $\mathrm{Mg}^{2+}$

D.W

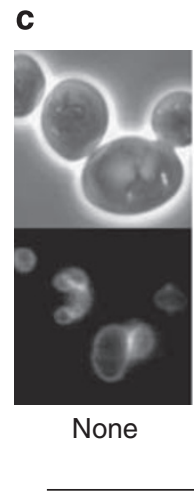

None

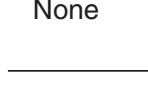

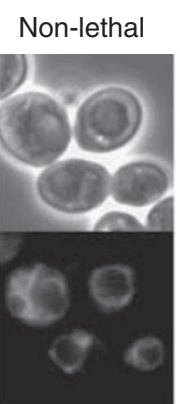

$\mathrm{AmB}$

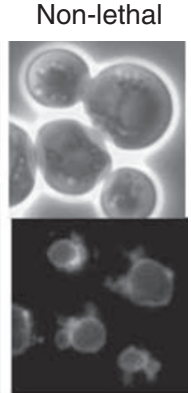

$\mathrm{AmB}$ + Allicin
D.W.

$\Delta$ erg6 cells

Figure 3 The effects of amphotericin $B(A m B)$ and the combination of $A m B$ and allicin on vacuole morphology in parent (a, b) and $\Delta$ erg6 (c) cells of S. cerevisiae. After treatment with the fluorescent dye FM4-64, cells $\left(1 \times 10^{7}\right.$ cells per ml) were incubated in distilled water (a, c), or in $85 \mathrm{~mm} \mathrm{KCl}$ and $45 \mathrm{~mm} \mathrm{MgCl} 2$ added to distilled water (b), each containing none, $5 \mu \mathrm{m} \mathrm{AmB}$ or a combination of $5 \mu \mathrm{m} \mathrm{AmB}$ and $120 \mu \mathrm{m}$ allicin at $30^{\circ} \mathrm{C}$ for $60 \mathrm{~min}$. Cells were observed under a bright-field microscope (top) and a fluorescence microscope (bottom). 


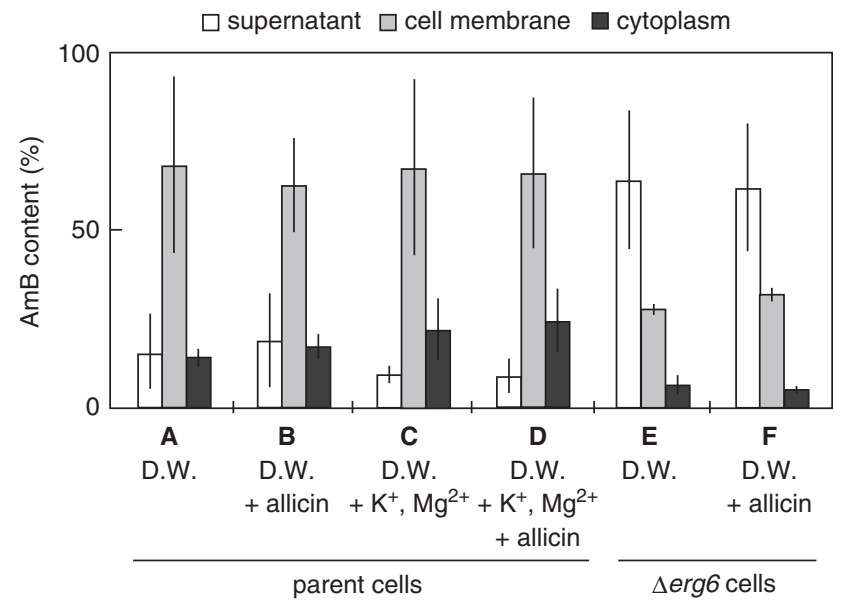

Figure 4 Subcellular localization of amphotericin $B(A m B)$ in parent (A-D) and $\Delta \operatorname{erg} 6(\mathrm{E}$ and $\mathrm{F})$ cells of $S$. cerevisiae. Cells $\left(1 \times 10^{8}\right.$ cells per $\left.\mathrm{ml}\right)$ were incubated in distilled water (A, B, E and F) or in distilled water added with $85 \mathrm{~mm} \mathrm{KCl}$ and $45 \mathrm{~mm} \mathrm{MgCl}_{2}$ ( $C$ and $D$ ), each containing $20 \mu \mathrm{m} \mathrm{AmB}$ in the absence $(A, C$ and $E)$ or presence $(B, D$ and $F)$ of $120 \mu \mathrm{m}$ allicin at $30^{\circ} \mathrm{C}$ for $60 \mathrm{~min}$. The $\mathrm{AmB}$ content in the supernatant (open bar), plasma membrane (gray bar) and cytoplasmic fractions (black bar) was determined by HPLC analysis. Data are expressed as the mean (s.d.) of the AmB content (\% of the total amount added to the cells) measured in triplicate assays. The AmB content of each fraction was statistically analyzed by Student's $t$-test, in which $P<0.05$ was considered statistically significant. Significant differences of $A m B$ content were identified on each fraction in parent and $\Delta$ erg6 cells.

$\mathrm{AmB}$ is known to depend on the leakage of intracellular $\mathrm{K}^{+}$, lethality in yeast cells seems to be related with vacuole disruption. Moreover, the existence of ergosterol in the plasma membrane is needed for vacuole disruption induced by $\mathrm{AmB}$ with or without allicin.

\section{Cellular uptake of AmB}

In our recent study using cells of $C$. albicans, we added AmB to the cell suspension to determine cellular uptake of AmB. AmB was mostly absent in the supernatant of the cell suspension after incubation for $60 \mathrm{~min}$. However, in the plasma membrane fractions, $\mathrm{AmB}$ was detected at a ratio of more than $80 \%$ of the initial quantity at 0 min. ${ }^{6}$ Further, the remaining $\mathrm{AmB}$ was quantitatively found in the cytoplasmic fraction. These results suggest that $\mathrm{AmB}$ permeates through the plasma membrane and invade the cytoplasm. In this study, we determined the subcellular uptake of AmB in parent and $\Delta$ erg6 cells in the presence or absence of $\mathrm{K}^{+}$and $\mathrm{Mg}^{2+}$. In this experiment, the concentrations of $\mathrm{AmB}$ were increased up to $20 \mu \mathrm{M}$ with increasing cell density up to $1 \times 10^{8}$ cells per $\mathrm{ml}$, owing to the sensitivity of HPLC analysis, which required the volume of AmB above a certain level. In agreement with our previous results, ${ }^{6}$ the major proportion of $\mathrm{AmB}$ was detected in the plasma membrane fraction of parent cells treated with $\mathrm{AmB}$, regardless of $\mathrm{K}^{+}$and $\mathrm{Mg}^{2+}$ supplementation (Figure 4, A and C). The addition of allicin did not affect the subcellular uptake of AmB in parent cells (Figure 4, B and D). On the other hand, in $\Delta$ erg 6 cells, the major proportion of AmB markedly remained in the supernatant; that is, the contents of $\mathrm{AmB}$ in the fractions of both plasma membrane and cytoplasm in $\Delta$ erg6 cells were significantly reduced in comparison with those in parent cells $(P<0.05)$, regardless of the presence of allicin (Figure $4, \mathrm{E}$ and $\mathrm{F})$. AmB could directly disrupt the isolated vacuoles of $S$. cerevisiae and $C$. albicans. ${ }^{6,12,13}$ Thus, taken together, these results suggest that the incorporation of $\mathrm{AmB}$ into the cytoplasm is at least needed for direct vacuole disruption and is restricted by the reduction of ergosterol in the plasma membrane; however, it is not affected by the presence of allicin or the intracellular levels of $\mathrm{K}^{+}$.

Our findings suggest that vacuole disruption correlates with cell death but not with changes in intracellular concentrations of $\mathrm{K}^{+}$. Vacuole disruption induced by the combination of AmB and allicin at least depended on the presence of ergosterol in the plasma membrane for the initial interaction with AmB. Our previous reports showed that allicin might enhance the fungicidal activity of $\mathrm{AmB}$ by inhibiting ergosterol trafficking from plasma membrane to vacuoles. ${ }^{12}$ Vacuole disruption induced by the combination of $\mathrm{AmB}$ and allicin may require both the reduction of ergosterol in the vacuole membrane and the presence of ergosterol in the plasma membrane. Moreover, these results might indicate that $\mathrm{AmB}$, as a vacuole-targeting antibiotic, cannot directly penetrate the plasma membrane but can be transported into the cytoplasm via interaction with ergosterol in the plasma membrane.

\section{ACKNOWLEDGEMENTS}

This study was supported, in part, by a Grant-in-Aid for Scientific Research (C) (number 20580083) from the Japan Society for the Promotion of Science.

1 Ghannoum, M. A. \& Rice, L. B. Antifungal agents: mode of action, mechanisms of resistance, and correlation of these mechanisms with bacterial resistance. Clin. Microbiol. Rev. 17, 501-517 (1999).

2 Carrillo-Muñoz, A. J., Giusiano, G., Ezkurra, P. A. \& Quindós, G. Antifungal agents: mode of action in yeast cells. Rev. Esp. Quimioter. 19, 130-139 (2006).

3 Brajtburg, J., Medoff, G., Kobayashi, G. S. \& Elberg, S. Influence of extracellular $\mathrm{K}^{+}$or $\mathrm{Mg}^{2+}$ on the stages of the antifungal effects of amphotericin B and filipin. Antimicrob. Agents Chemother. 18, 593-597 (1980).

4 Alonso, M. A., Vázquez, D. \& Carrasco, L. Compounds affecting membranes that inhibit protein synthesis in yeast. Antimicrob. Agents Chemother. 16, 750-756 (1979).

5 Okamoto, Y., Aoki, S. \& Mataga, I. Enhancement of amphotericin B activity against Candida albicans by superoxide radical. Mycopathologia 158, 9-15 (2004).

6 Borjihan, H., Ogita, A., Fujita, K., Hirasawa, E. \& Tanaka, T. The vacuole-targeting fungicidal activity of amphotericin B against the pathogenic fungus Candida albicans and its enhancement by allicin. J. Antibiot. 62, 691-697 (2009).

7 Baginski, M., Czub, J. \& Sternal, K. Interaction of amphotericin B and its selected derivatives with membranes: molecular modeling studies. Chem. Rec. 6, 320-332 (2006).

$8 \mathrm{Liu}, \mathrm{T}$. T. et al. Genome-wide expression profiling of the response to azole, polyene, echinocandin, and pyrimidine antifungal agents in Candida albicans. Antimicrob. Agents Chemother. 49, 2226-2236 (2005).

9 Ankri, S. \& Mirelman, D. Antimicrobial properties of allicin from garlic. Microbes Infect. 1, 125-129 (1999).

10 Oommen, S., Anto, J. R., Srinivas, G. \& Karunagaran, D. Allicin (from garlic) induces caspase-mediated apoptosis in cancer cells. Eur. J. Pharmacol. 485, 97-103 (2004).

11 Ogita, A., Fujita, K., Taniguchi, M. \& Tanaka, T. Enhancement of the fungicidal activity of amphotericin B by allicin, an allyl-sulfur compound from garlic, against the yeast Saccharomyces cerevisiae as a model system. Planta Med. 72, 1247-1250 (2006).

12 Ogita, A., Fujita, K. \& Tanaka, T. Enhancement of the fungicidal activity of amphotericin B by allicin: effects on intracellular ergosterol trafficking. Planta Med. 75, 222-226 (2009).

13 Ogita, A., Fujita, K., Usuki, Y. \& Tanaka, T. Targeted yeast vacuole disruption by polyene antibiotics with a macrocyclic lactone ring. Int. J. Antimicrob. Agents. 35, 89-92 (2010).

14 Ramotowski, S. \& Szczesniak, M. Determination of potassium salt content in pharmaceutical preparations by means of sodium tetraphenylborate. Acta. Pol. Pharm. 24, 605-613 (1967).

15 Ogita, A. et al. Synergistic fungicidal activities of amphotericin B and $N$-methyl- $N^{\prime \prime}$ dodecylguanidine: a constituent of polyol macrolide antibiotic niphimycin. J. Antibiot. 60, 27-35 (2007)

16 Esposito, E., Bortolotti, F., Menegatti, E. \& Cortesi, R. Amphiphilic association systems for amphotericin B delivery. Int. J. Pharm. 260, 249-260 (2003).

17 Romero, P. J. The role of membrane-bound magnesium in the permeability of ghosts to $\mathrm{K}^{+}$. Biochim. Biophys. Acta. 339, 116-125 (1974).

18 Suomalainen, H. \& Oura, E. in The Yeasts. Yeast nutrition and solute uptake, physiology and biochemistry of yeasts (eds Rose, A.H. \& Harrison J.S.) 3-74 (Academic Press Inc., New York, 1971).

19 Young, L. Y., Hull, C. M. \& Heitman, J. Disruption of ergosterol biosynthesis confers resistance to amphotericin B in Candida Iusitaniae. Antimicrob. Agents Chemother. 47, 2717-2724 (2003).

20 Baginski, M., Sternal, K., Czub, J. \& Borowski, E. Molecular modelling of membrane activity of amphotericin B, a polyene macrolide antifungal antibiotic. Acta. Biochimica. Polonica. 52, 655-658 (2005). 